Donnie Jan D. Segocio, MD

Joseph E. Cachuela, MD

Department of Otorhinolaryngology

Head and Neck Surgery

Southern Philippines Medical Center

\section{Levothyroxine versus Levothyroxine with lodine in Reduction of Thyroid Nodule Volume: A Double-Blind Randomized Controlled Trial}

\begin{abstract}
Objective: To compare levothyroxine alone and in combination with iodine on thyroid nodule volume reduction.

Methods:

$\begin{array}{ll}\text { Design: } & \text { Double-Blind Randomized Controlled Trial } \\ \text { Setting: } & \text { Tertiary Government Hospital }\end{array}$

Participants: Nineteen (19) euthyroid patients age 19-54 with at least 1 cytologically benign thyroid nodule were randomized to receive either levothyroxine + iodine or levothyroxine + placebo, taken once a day for 6 months with ultrasound and thyroid stimulating hormone monitoring on the $3^{\text {rd }}$ and $6^{\text {th }}$ month of intervention.
\end{abstract}

Results: Main outcome measures included thyroid nodule volume reduction after six months of intervention. The mean change in volume from baseline to six months of levothyroxine + iodine group showed no statistically significant difference in nodule volume across time between levothyroxine + placebo group, $-0.010 \pm 1.250(\mathrm{Cl}-0.521-0.501)$ versus $0.507 \pm 1.128(\mathrm{Cl} 0.025-$ $0.990), p=.158$. There were also new nodules ( 4 nodules) in the placebo group and none in the iodine group. No major adverse events were noted during the study.

Conclusion: The two groups did not significantly differ in terms of nodule volume reduction.

Keywords: thyroid nodule, prevention and control; drug therapy; iodine compounds, therapeutic use; levothyroxine, therapeutic use

Thyroid nodules are among the most common endocrine disorders. In the general population, the incidence of clinically apparent thyroid nodule is 4 to $75 \%$ although autopsy studies reveal a higher percentage of about $50 \%$ with thyroid nodularity. ${ }^{1}$ The rates may be even higher in endemic goiter areas or those with iodine deficiency areas. ${ }^{2}$ In the Philippines, $6.6 / 100,000$ of the general population have a thyroid mass with female predominance of $9.8 / 100,000$ compared to males $3.1 / 100,000 .^{3}$ Despite being common worldwide, there is still no consensus with regards to the management of thyroid nodules. Several clinical trials have 
demonstrated the efficacy of levothyroxine suppression therapy in shrinking nodules. $4,5,6$ However, there are also studies which showed contradicting results ${ }^{7,8}$ thus making the appropriate course of action controversial. Results could be affected by several factors such as the degree of suppression and the individual's iodine supply status. Thus, one study recommended combining thyroid hormone suppression therapy with iodine therapy on the premise that iodine plays an important role in the pathogenesis of thyroid nodules. ${ }^{4}$

Despite government efforts in iodine food fortification to reduce iodine deficiency in the Philippines, certain areas of the country remain iodine deficient. Among these areas is the Davao region where children six to twelve years old still have mild iodine-deficiency disease. ${ }^{9}$ Data regarding the use of iodine for thyroid nodules especially in combination with levothyroxine is lacking in the Philippines and even in Asian countries. The use of iodine alone or in combination with levothyroxine is not even part of the treatment options recommended in our local guidelines for thyroid nodule management. ${ }^{10}$ The study by Grussendorf ${ }^{4}$ comparing levothyroxine with and without iodine showed reduction in the size of nodules in nodular non-toxic goiter. Validating foreign recommendations against local data is an important step in ensuring the best clinical practices for important diseases.

To the best of our knowledge, there has been no placebo-controlled trial using levothyroxine with iodine therapy for nodular goiters in our locality, which is known to be mildly iodine deficient. We aim to replicate the study of Grussendorf ${ }^{4}$ by comparing levothyroxine alone and in combination with iodine on thyroid nodule volume reduction.

\section{METHODS}

\section{Research Design}

This was a double-blind, randomized, placebo-controlled trial conducted in the Ear, Nose, Throat - Head and Neck Surgery (ENTHNS) outpatient department of the Southern Philippines Medical Center (SPMC) from April 2016 to December 2016 with approval of the Department of Health (DOH) Region XI Cluster Ethics Review Committee.

\section{Participants}

Adults aged 18 to 60 years old, euthyroid, with at least one thyroid nodule in a normal-sized or enlarged thyroid were considered for inclusion. The nodules had to be histopathologically benign on fineneedle aspiration biopsy (FNAB) and not more than $3 \mathrm{ml}$ in volume. Excluded were patients with prior thyroid stimulating hormone (TSH) suppression therapy within the last six (6) months, purely cystic nodules, those with contraindications to iodine, those with previous

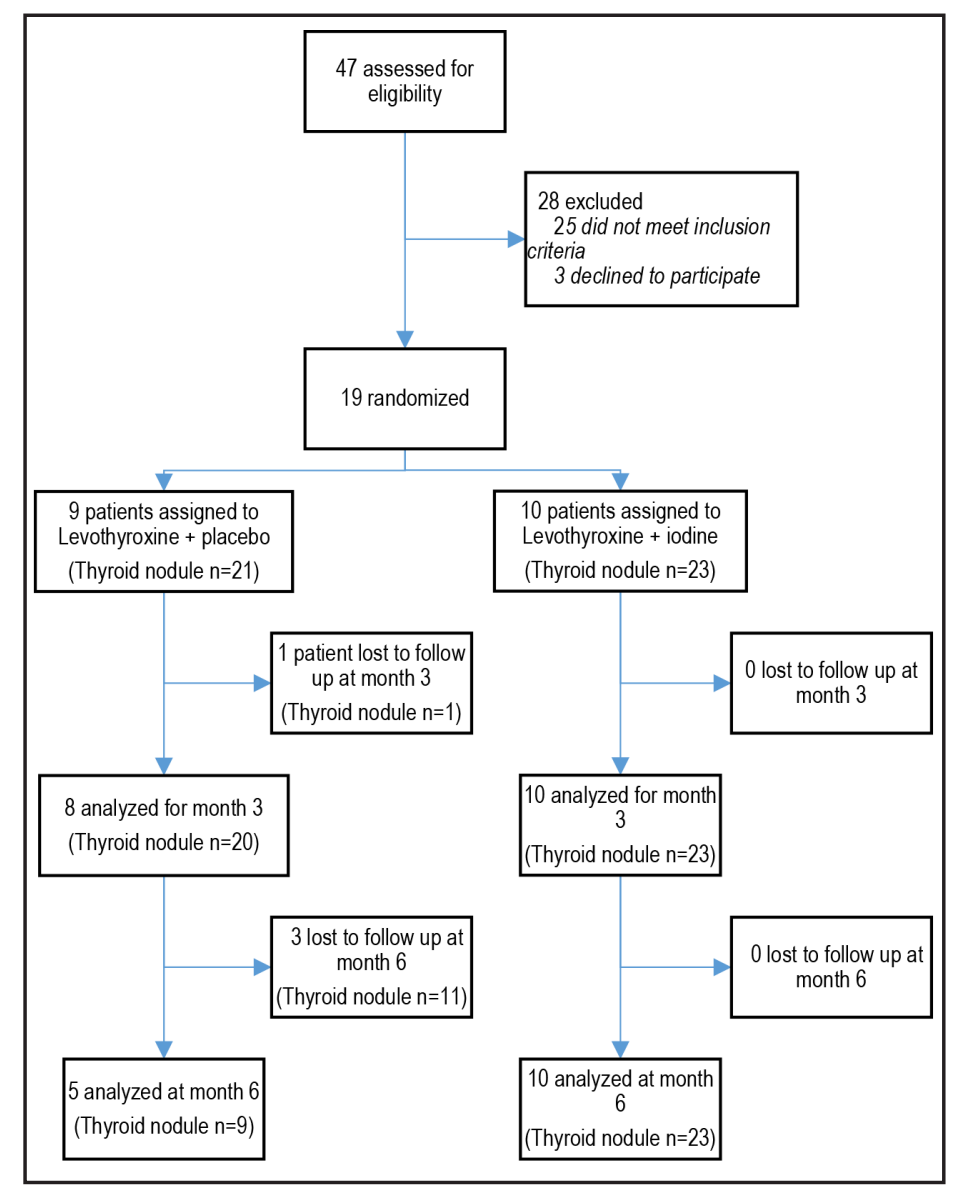

Figure 1. Screening, randomization and follow-up of participants

use of iodine-containing medications within the last 6 weeks, or who underwent radioactive iodine/surgery, and patients with acute illness and co-morbidities. Figure 1 outlines the screening, randomization and follow up of participants.

\section{Randomization and Interventions}

After obtaining informed consent from participants, we gathered baseline demographic and clinical data including age, sex, family history of goiter, thyroid nodule volume, thyroid gland volume and TSH value.

A randomization list was prepared and given to a nurse assistant who assigned the treatment for groups $A$ and $B$ and prepared treatments according to the randomization list. Placebo pills were identical in appearance to iodine pills. Patients were randomly assigned to either one of the following treatment arms:

Treatment group A: (LT4) levothyroxine + (P) placebo Treatment group B: (LT4) levothyroxine + (I) iodine 
The nurse also dispensed the treatment drugs. The investigators and participants were blinded to treatment arms. Randomization codes were secured until analysis of all data was completed.

TSH suppressive dosage was computed using the participant's weight 2 2.1-2.4, depending on the degree of suppression. Levothyroxine (LT4) doses were adjusted for a TSH target range of $<0.1 \mathrm{mU} / \mathrm{L}$.

Four visits were performed: screening (V1), randomization (V2), and two follow-up visits under therapy after 3 (V3) and 6 months (V4). At V1, V3 and V4, sonography was performed by a blinded radiology consultant who was an ultrasound specialist, using Arietta U70 HITACHI with a 7.5- or 10- MHz transducer (HIMEX Corporation, Japan). The same blinded sonologist measured the thyroid size and thyroid nodule volume all throughout the study period. TSH was measured at V1, V3, and $\mathrm{V} 4$ in a central laboratory under regular external quality control. At each follow-up, a pill diary and any unused medications were collected and counted to estimate patient compliance.

Data was tabulated using a predesigned, pretested form. Independent variables included demographic factors such as age, sex, family history of thyroid disease and the assigned treatment group. The main outcome measure was the volume reduction of nodules measured by ultrasound. Resolution was defined as complete disappearance of previously described nodule for the duration of the study. Significant nodule volume reduction was defined as reduction of at least $20 \%$ of nodule volume from the baseline for the duration of the study. Furthermore, the different side effects encountered while taking the drug were reported.

\section{Statistical Analysis}

Main outcome include mean change in thyroid nodule volume from baseline to 6 months. Continuous data such as age, TSH values, thyroid nodule volume, thyroid gland volume at baseline, 3 months and 6 months were summarized as means \pm standard deviations. Comparison of means between the 2 treatment groups were performed using paired t-test. Categorical data such as sex, number of nodules, family history and percentage of decrease in nodule volume at end of 6 months were summarized using frequencies and percentages, and comparison of proportions between the 2 treatment groups was performed using Chi-square test or Fisher exact test. A two-tailed $p$-value of $<.05$ was considered statistically significant. All statistical tests were done using Epi Info 7.1.4.0 (CDC, Atlanta, GA, USA). Missing continuous data were filled in by last-observation-carried-forward method.

\section{Patient Characteristics}

\section{RESULTS}

A total of 47 patients were screened but only 19 patients, aged 19-54 years old (44 nodules) were included in the study. A total of 28 patients were excluded following exclusion criteria. The 19 patients recruited into the trial were randomized either to the levothyroxine + placebo group ( $\mathrm{n}$ of patients $=9 ; \mathrm{n}$ of thyroid nodules $=21$ ) or to the levothyroxine with iodine group ( $n$ of patients $=10$; $n$ of thyroid nodule $=23$ ). There were 4 dropouts from the levothyroxine alone group for the duration of the study comprising 3 patients with data up to 3 months only and 1 patient who was lost to follow-up on the $3^{\text {rd }}$ month. There was also one patient from the levothyroxine with iodine group who failed to have repeat ultrasound on the $6^{\text {th }}$ month and was lost to follow-up. Four patients belonging to the levothyroxine with iodine group and 3 patients belonging to the levothyroxine alone group were noted to be poorly compliant with the intervention. Of the adverse effects, only palpitations were reported by $16 \%$ (3 out of 19) of participants, 1 from the levothyroxine alone group and 2 from the levothyroxine with iodine group.

Baseline characteristics of the 19 patients are shown in Table 1. There was no significant difference in baseline characteristics between the two groups except for age $(p=.018)$.

A total of 44 nodules were observed during the study. There were 23 nodules examined from the LT4 + iodine group ( $\mathrm{n}$ of patients $=10$ ) with a mean volume of $0.89 \pm 0.95 \mathrm{ml}$ and 21 nodules in the LT4 + placebo group ( $n$ of patients $=9$ ) with a mean volume of $0.89 \pm 0.88 \mathrm{ml}(p=.988)$.

\section{Patient Follow up}

On the third month, one patient (having one nodule) from the levothyroxine + placebo group was lost to follow up. By the sixth month post-intervention, a total of three patients (having 11 nodules) from the levothyroxine + placebo group were lost to follow up. Hence, perprotocol analysis of the outcome measures only included 5 patients $(9$ nodules) from the levothyroxine + placebo group. No drop-outs were seen on the levothyroxine + iodine group.

\section{Thyroid Nodule Volume}

The mean change in volume from baseline to six months of levothyroxine + iodine group showed a trend of decreasing size of the nodule as compared to levothyroxine + placebo group, $-0.010 \pm 1.250$ $(\mathrm{Cl}-0.521-0.501)$ versus $0.507 \pm 1.128(\mathrm{Cl} 0.025-0.990)$, however this was not statistically significant ( $p=.158)$. (Table 2 ) 
ORIGINAL ARTICLES

Table 1. Demographic and clinical profile of patients at the beginning of the trial

\begin{tabular}{|l|c|c|l|}
\hline \multicolumn{1}{|c|}{ Characteristics } & $\begin{array}{c}\text { Levothyroxine }+ \\
\text { iodine } \\
\text { (n of patients=10) } \\
\text { (n of nodule =23) }\end{array}$ & $\begin{array}{c}\text { Levothyroxine }+ \\
\text { placebo } \\
\text { (n of patients=9) } \\
\text { (n of nodule = 21) }\end{array}$ & p-value \\
\hline Mean age \pm SD, years & $45.40 \pm 5.98$ & $35.78 \pm 9.81$ & $.018^{*}$ \\
\hline Sex, frequency (\%) & 0 & 0 & - \\
\hline \multicolumn{1}{|c|}{ Male } & $10(100.00)$ & $9(100.00)$ & - \\
\hline $\begin{array}{l}\text { Family history, } \\
\text { frequency }(\%)\end{array}$ & $4 / 10(40 \%)$ & $6 / 9(66.67 \%)$ & $.369^{* *}$ \\
\hline $\begin{array}{l}\text { Number of nodules per } \\
\text { person }\end{array}$ & $2.40 \pm 0.43$ & $2.44 \pm 0.60$ & .952 \\
\hline $\begin{array}{l}\text { Mean thyroid nodule } \\
\text { volume } \pm \text { SD, mL }\end{array}$ & $0.89 \pm 0.95$ & $0.89 \pm 0.88$ & .988 \\
\hline $\begin{array}{l}\text { Mean thyroid gland } \\
\text { volume } \pm \text { SD, mL }\end{array}$ & $8.21 \pm 7.30$ & $6.69 \pm 4.33$ & .445 \\
\hline $\begin{array}{l}\text { Mean TSH } \pm \text { SD, } \\
\text { mIU/L }\end{array}$ & $1.07 \pm 0.45$ & $1.52 \pm 0.52$ & .059 \\
\hline \multirow{*}{*}{ Significantly different at $<0.05$} \\
$*$ Fisher exact test
\end{tabular}

\section{Thyroid Gland Volume}

A trend of decreasing thyroid gland volume from baseline to six months was also seen in the levothyroxine + iodine group as compared to the levothyroxine + placebo group, $-1.291 \pm 4.874$ (Cl $-3.427-0.845$ ) versus $1.467 \pm 4.059(\mathrm{Cl}-0.408-3.342)$ and but this was not significant $(\mathrm{p}=.068)$. (Table 2$)$

\section{TSH Suppression}

TSH suppression from baseline to six months when comparing both groups, was well suppressed in the levothyroxine + placebo group with mean change in TSH of $-0.937 \pm 0.812$ and a confidence interval of -1.467 to -0.406 ( $p$-value for change $.007^{*}$ ) and $-0.256 \pm 0.733$ for the levothyroxine + iodine group ( $\mathrm{Cl}-0.711-0.199)$. However, this was not statistically significant. $(\mathrm{p}=.072$ ). (Table 2 )

\section{Greater Than 20\% Reduction}

Greater than 20\% nodule volume reduction was noted in 10/21 (47.6\%) nodules for the levothyroxine + iodine group as compared to $7 / 21$ (33.33\%) for the levothyroxine + placebo group, (granting all dropouts had the outcome), with $4 / 48$ (8.33\%) without any change in volume. However, this was not statistically significant (Chi-square value of $1.96, \mathrm{df}=2, \mathrm{p}=.375$ ). (Table 3 )

\section{Resolution}

Resolution was noted in five out of twenty-three (21.74\%) nodules from the levothyroxine + iodine group as compared to 13/21 (61.90\%) from the levothyroxine + placebo group, granting all dropouts had the outcome. This is statistically significant with $p$-value of $.007^{*}$. However, this was not the same with per protocol analysis excluding the dropouts, where only $1 / 9(11.11 \%)$ nodules showed resolution with $p$-value of $.648^{* *}$ (chi-square 7.3259), which was not statistically significant when both groups were compared.

\section{Adverse Effects}

Twenty percent $(2 / 10)$ of patients in the iodine group complained of palpitations in the first month of intervention, compared to $11 \%(1 / 9)$ of patients from the placebo group. This patient complaint led to dose adjustment of levothyroxine that could be well tolerated. For patients who could not tolerate suppressive doses without experiencing palpitations, doses were tapered as tolerated. No other adverse effects were observed in both groups.

\section{New Nodule Formation}

It was worth noting that for the duration of six months of treatment for both groups, 4 new nodules were found in 2 patients ( 1 nodule 
ORIGINAL ARTICLES

Philippine Journal Of Otolaryngology-Head And Neck Surgery

VOL. 34 No. 1 JANUARY - JUNE 2019

PJOHLS

Table 2. Effect of the different treatment groups versus placebo on the nodule volume, thyroid volume and thyroid function at 6 th month

\begin{tabular}{|c|c|c|c|c|c|c|c|}
\hline \multirow[t]{2}{*}{ Characteristics } & \multicolumn{2}{|c|}{$\begin{array}{c}\text { T4+lodine } \\
(n=10) \\
\text { (Thyroid } n=20) \\
\text { (Nodule } n=23 \text { ) }\end{array}$} & \multicolumn{2}{|c|}{$\begin{array}{l}\text { T4+placebo } \\
(n=9) \\
(\text { Thyroid } n=18) \\
\text { (Nodule } n=21 \text { ) }\end{array}$} & \multirow[t]{2}{*}{ df } & \multirow[t]{2}{*}{$\begin{array}{l}\mathrm{t}- \\
\text { statistic } \\
\mathrm{s}\end{array}$} & \multirow[t]{2}{*}{$\begin{array}{c}\mathrm{p}- \\
\text { value }\end{array}$} \\
\hline & Mean \pm SD & $\begin{array}{c}\text { Confidence } \\
\text { interval }\end{array}$ & Mean \pm SD & $\begin{array}{c}\text { Confidence } \\
\text { interval }\end{array}$ & & & \\
\hline \multicolumn{8}{|l|}{ Nodule volume } \\
\hline Baseline & $0.899 \pm 0.947$ & $0.512-1.286$ & $0.895 \pm 0.877$ & $0.520-1.270$ & 42 & 0.015 & .988 \\
\hline 3 months & $0.851 \pm 1.074$ & $0.412-1.290$ & $1.061 \pm 1.148$ & $0.569-1.552$ & 42 & -0.626 & .535 \\
\hline 6 months & $0.889 \pm 1.329$ & $0.346-1.432$ & $1.402 \pm 1.738$ & $0.659-2.146$ & 42 & -1.106 & .275 \\
\hline $\begin{array}{l}\text { Change in volume from } \\
\text { baseline to } 6 \text { months }\end{array}$ & $-0.010 \pm 1.250$ & $-0.521-0.501$ & $0.507 \pm 1.128$ & $0.025-0.990$ & 42 & -1.436 & .158 \\
\hline$p$-value for change & .977 & & .239 & & & & \\
\hline \multicolumn{8}{|l|}{ Thyroid volume } \\
\hline Baseline & $8.211 \pm 7.298$ & $5.012-11.410$ & $6.686 \pm 4.330$ & $4.686-8.687$ & 36 & 0.772 & .445 \\
\hline 3 months & $7.647 \pm 5.136$ & $5.396-9.899$ & $7.987 \pm 6.385$ & $5.037-10.937$ & 36 & -0.182 & .857 \\
\hline 6 months & $6.920 \pm 5.227$ & $4.629-9.211$ & $8.153 \pm 7.331$ & $4.767-11.540$ & 36 & -0.602 & .551 \\
\hline $\begin{array}{l}\text { Change in volume from } \\
\text { baseline to } 6 \text { months }\end{array}$ & $-1.291 \pm 4.874$ & $-3.427-0.845$ & $1.467 \pm 4.059$ & $-0.408-3.342$ & 36 & -1.883 & .068 \\
\hline$p$-value for change & .524 & & .469 & & & & \\
\hline \multicolumn{8}{|l|}{ TSH } \\
\hline Baseline & $1.070 \pm 0.448$ & $0.793-1.347$ & $1.517 \pm 0.515$ & $1.180-1.853$ & 17 & -2.023 & .059 \\
\hline 3 months & $0.432 \pm 0.677$ & $0.013-0.851$ & $0.251 \pm 0.582$ & $-0.129-0.631$ & 17 & 0.621 & .543 \\
\hline 6 months & $0.814 \pm 0.972$ & $0.211-1.417$ & $0.580 \pm 0.744$ & $0.094-1.066$ & 17 & 0.584 & .567 \\
\hline $\begin{array}{l}\text { Change in volume from } \\
\text { baseline to } 6 \text { months }\end{array}$ & $-0.256 \pm 0.733$ & $-0.711-0.199$ & $\begin{array}{l}-0.937 \pm \\
0.812 \\
\end{array}$ & $-1.467--0.406$ & 17 & 1.92 & .072 \\
\hline$p$-value for change & .459 & & $.007^{*}$ & & & & \\
\hline
\end{tabular}

rat $<0.05$

*Significantly different at $<0.05$

**Fisher exact test

\# Intention-to-treat analysis - all dropouts has the outcome

Table 3. Distribution of percent change in thyroid nodule volume between the two treatments

\begin{tabular}{|c|c|c|c|}
\hline $\begin{array}{c}\text { Thyroid nodule volume } \\
\text { change }\end{array}$ & $\begin{array}{c}\text { T4+lodine } \\
(\mathbf{n = 1 0 )} \\
(\text { Thyroid } \mathbf{n = 2 0}) \\
\text { (Nodule } \mathbf{n = 2 3 )}\end{array}$ & $\begin{array}{c}\text { T4+placebo } \\
\mathbf{( n = 9 )} \\
(\text { Thyroid } \mathbf{n = 1 8 )} \\
\text { (Nodule } \mathbf{n = 2 1 )}\end{array}$ & Total \\
\hline $20 \%$ decrease & $10 / 23$ & $7 / 21$ & $85.91 \pm 37.43$ \\
\hline Mean decrease (\%) & $85.11 \pm 20.52$ & $87.06 \pm 55.7$ & $40.91-200$ \\
\hline Min/Max (\%) & $40.91-200$ & $41.86-200$ & 4 \\
\hline No change & $3 / 23$ & $1 / 21$ & 17 \\
\hline & & & $152.85 \pm 301.82$ \\
\hline Increase in size & $7 / 23$ & $10 / 21$ & $1.92-1156$ \\
\hline Mean increase (\%) & $119.79 \pm 203.95$ & $178.57 \pm 371.36$ & \\
\hline Min/Max (\%) & $1.92-568$ & $3.7-1156$ & 38 \\
\hline
\end{tabular}

Chi square $1.96, \mathrm{df}=2 \mathrm{p}=.375$ 
in 1 patient and 3 nodules on another patient) belonging to the levothyroxine + placebo group.

\section{DISCUSSION}

We did this study in order to find out whether the addition of iodine to levothyroxine in the management of benign thyroid nodules for the duration of six months would have better results compared to levothyroxine alone. There were no statistically and clinically significant differences between those given levothyroxine and levothyroxine with iodine for 6 months, in terms of $20 \%$ nodule volume reduction, glandular volume and occurrence of palpitations. Four new nodules were also noted in the placebo group with none in the iodine group.

The effectiveness of levothyroxine given in suppressive doses in reducing the size of thyroid nodules remains controversial. Many studies have conflicting results. ${ }^{4}$ The addition of iodine in the treatment of thyroid nodules and its effectiveness remains unclear, as we have not found sound recommendations for doing so. A similar (but multicenter) study in Germany with 12 months follow-up of more than 1024 patients comparing levothyroxine with or without iodine provided promising results even in iodine sufficient areas, showing reduction in nodule volume, however minimal. ${ }^{4}$ When compared after six months of intervention, there was a significant difference favoring the iodine group over the placebo group in terms of thyroid nodule volume reduction. ${ }^{4}$ After 6 months of intervention, a trend was also noted for levothyroxine with placebo, with nodule volume and gland volume showing increase in size and appearance of new nodules despite TSH suppression, in contrast to the levothyroxine with iodine group, which showed decrease in size of nodule volume and thyroid gland volume with adequate TSH suppression. Our study only employed a 6-month follow-up of patients with limited sample size for each arm. Hence, the variability in the outcomes measured. In another study, the possibility of prevention of new nodule formation is suggested by the levothyroxine + iodine group results as new nodule formation was not prevented in the placebo group ${ }^{11}$ similar to our study findings.

The TSH was not adequately suppressed in 6 patients ( 2 from the placebo group and 4 from the iodine group) because of poor compliance and palpitations requiring dose adjustment. However, most of these patients showed increasing nodule size after 6 months of intervention in contrast to the findings by Koc et al. in 2002, that low or high-dose levothyroxine was equally effective in reducing thyroid nodule volume, recommending the use of low-dose therapy to reduce thyroid nodule size. ${ }^{12}$

Our study has several limitations. We presented data for 6-months duration of intervention. We were unable to demonstrate statistical significance in comparing both groups especially in terms of thyroid nodule volume reduction. This is probably related to the limited power of the study to generate inferences from only those patients who were able to return for follow up assessment. We had 4 drop outs during the study, and 7 patients were poorly compliant. The study population was adequate at the start of the study and up to 3 months only, especially for the levothyroxine + placebo group. We were also unable to recruit any male patients for the study.

We recommend multicenter trials involving more patients, a longer duration of intervention extended to 1 year with better treatment compliance, and monthly follow-up to adjust dosage to attain suppressive doses of levothyroxine. Other parameters like measurement of iodine excretion in the urine to establish degree of iodine deficiency, measurement of thyroglobulin level at baseline and its decrease as a useful predictor of outcome in levothyroxine therapy may be included. We further recommend that nodule volume reduction be studied using suppressive and non-suppressive doses of levothyroxine.

In conclusion, in this randomized controlled trial, there were no significant differences between levothyroxine alone versus levothyroxine with iodine; the two groups did not significantly differ in terms of thyroid nodule volume reduction.

\section{ACKNOWLEDGEMENTS}

We would like to extend our deepest gratitude to Dr. Alvin S Concha for his guidance in the completion of this research. We would also like to thank the Southern Philippines Medical Center as well as the Southern Mindanao Chapter of the Philippine Society of Otolaryngology Head and Neck Surgery (PSO-HNS) for their support in this study.

\section{REFERENCES}

1. Singer PA. Evaluation and management of the solitary thyroid nodule. Otolaryngol Clin North Am. 1996;29(4):557-91.

2. Larijani B, Pajouhi M, Bastanhagh MH, Sadjadi A, Aghakhani S, Zare F, et. al. Role of Levothyroxine suppressive therapy for benign cold nodules of thyroid: a randomized, double-blind, placebocontrolled clinical trial. Therapy. 2005. 2(6): 883-888. DOI: 10.1586/14750708.2.6.883

3. Caro RM, Jose EM, Llanes EGDV, Arquiza CJS, Calaquian CME, Claridad JRV, et al. UP-PGH Department of Otorhinolaryngology Clinical Practice Guidelines Thyroid nodules. 2003. Caliraya Laguna: Philippine General Hospital. 30-39.

4. Grussendorf M, Reiners C, Paschke R, Wegscheider K. Reduction of thyroid nodule volume by levothyroxine and iodine alone and in combination: a randomized, placebo-controlled trial. Clin Endocrinol Metab. 2011 Sep; 96(9):2786-2795. DOI: 10.1210/jc.2011-0356; PMID: 21715542 PMCID: PMC3206705

6. Wémeau JL, Caron P, Schvartz C, Schlienger JL, Orgiazzi J, Cousty C, et al. Effects of thyroidstimulating hormone suppression with levothyroxine in reducing the volume of solitary thyroid nodules and improving extranodular nonpalpable changes: a randomized, double-blind placebo-controlled trial by the French Thyroid Research Group. J Clin Endocrinol Metab. 2002 Nov; 87(11):4928-4934. DOI: 10.1210/jc.2002-020365; PMID: 12414852.

7. Bayani M, Amani M, Moazezi Z. Efficacy of levothyroxine on benign thyroid nodule. Caspian J Intern Med. 2012;3(1):359-362.

8. Reverter JL, Lucas A, Salinas I, Audí L, Foz M, Sanmartí A. Suppressive therapy with levothyroxine for solitary thyroid nodules. Clin Endocrinol (Oxf). 1992 Jan;36(1):25-8.

9. Perlas L, Capanzana M. Careful Quantitative Monitoring of Salt lodine Levels in the Philippines is Critical to Ensure Adequate lodine Intake. IDD Newsletter. FNRI-DOST: Manila. 2011.

10. Lopez FL, Ampil IDE, Aquino MLD, De los Santos NC, Castañeda SS, Claridad JRV, et al. The PCSPSGS-PAHNSI Evidence-Based Clinical Practice Guidelines on Thyroid Nodules. Philipp J Surg Spec. 2008 Jul-Sep; 63(3): 91-125.

11. Uy JD, Mercado-Asis LB. Prevention of Recurrence of diffuse and nodular nontoxic goiter with lifetime Physiologic Levothyroxine Maintenance. Philipp J Intern Med. 2009. 47:207-210.

12. Koc M, Ersoz HO, Akpinar I, Gogas-Yavuz D, Deyneli O, Akalin S. Effect of low- and high-dose levothyroxine on thyroid nodule volume: a crossover placebo-controlled trial. Clin Endocrinol (Oxf). 2002 Nov; 57(5):621-8. PMID: 12390336. 